OPEN ACCESS

Edited by:

Takuro Nunoura

Japan Agency for Marine-Earth

Science and Technology, Japan

Reviewed by:

Satoshi Ishii,

University of Minnesota Twin Cities,

United States

Hidetoshi Urakawa,

Florida Gulf Coast University,

United States

Katrin Wendt-Potthoff,

Helmholtz Centre for Environmental

Research (UFZ), Germany

*Correspondence:

Lesley A. Warren

lesley.warren@utoronto.ca

tPresent address:

Jiro F. Mori,

Graduate School of Nanobiosciences, Yokohama City University, Yokohama,

Japan

Gerdhard L. Jessen,

Facultad de Ciencias, Instituto de Ciencias Marinas y Limnológicas, Universidad Austral de Chile, Valdivia,

Chile

Specialty section:

This article was submitted to

Aquatic Microbiology,

a section of the journal

Frontiers in Microbiology

Received: 24 July 2019 Accepted: 09 October 2019

Published: 24 October 2019

Citation:

Mori JF, Chen L-X, Jessen GL,

Rudderham SB, McBeth JM, Lindsay MBJ, Slater GF, Banfield JF

and Warren LA (2019) Putative

Mixotrophic Nitrifying-Denitrifying

Gammaproteobacteria Implicated

in Nitrogen Cycling Within

the Ammonia/Oxygen Transition Zone

of an Oil Sands Pit Lake.

Front. Microbiol. 10:2435.

doi: 10.3389/fmicb.2019.02435

\section{Putative Mixotrophic} Nitrifying-Denitrifying Gammaproteobacteria Implicated in Nitrogen Cycling Within the Ammonia/Oxygen Transition Zone of an Oil Sands Pit Lake

\author{
Jiro F. Mori't, Lin-Xing Chen², Gerdhard L. Jessen ${ }^{1 \dagger}$, Sarah B. Rudderham ${ }^{3}$, \\ Joyce M. McBeth ${ }^{3}$, Matthew B. J. Lindsay ${ }^{3}$, Gregory F. Slater ${ }^{4}$, Jillian F. Banfield² and \\ Lesley A. Warren ${ }^{1,4 *}$
}

${ }^{1}$ Department of Civil and Mineral Engineering, University of Toronto, Toronto, ON, Canada, ${ }^{2}$ Department of Earth and Planetary Sciences, University of California, Berkeley, Berkeley, CA, United States, ${ }^{3}$ Department of Geological Sciences, University of Saskatchewan, Saskatoon, SK, Canada, ${ }^{4}$ School of Geography and Earth Science, McMaster University,

Hamilton, ON, Canada

Anthropogenically-impacted environments offer the opportunity to discover novel microbial species and metabolisms, which may be undetectable in natural systems. Here, a combined metagenomic and geochemical study in Base Mine Lake, Alberta, Canada, which is the only oil sands end pit lake to date, revealed that nitrification was performed by members from Nitrosomonadaceae, Chloroflexi and unclassified Gammaproteobacteria "MBAE14." While Nitrosomonadaceae and Chloroflexi groups were relatively abundant in the upper oxygenated zones, MBAE14 dominated the hypoxic hypolimnetic zones (approximately $30 \%$ of total microbial communities); MBAE14 was not detected in the underlying anoxic tailings. Replication rate analyses indicate that MBAE14 grew in metalimnetic and hypolimnetic water cap regions, most actively at the metalimnetic, ammonia/oxygen transition zone consistent with it putatively conducting nitrification. Detailed genomic analyses of MBAE14 evidenced both ammonia oxidation and denitrification into dinitrogen capabilities. However, the absence of known $\mathrm{CO}_{2}$-fixation genes suggests a heterotrophic denitrifying metabolism. Functional marker genes of ammonia oxidation (amo and hao) in the MBAE14 genome are homologous with those conserved in autotrophic nitrifiers, but not with those of known heterotrophic nitrifiers. We propose that this novel MBAE14 inhabits the specific ammonia-rich, oxygen and labile organic matter-limited conditions occurring in Base Mine Lake which selectively favors mixotrophic coupled nitrifier denitrification metabolism. Our results highlight the opportunities to better constrain biogeochemical cycles from the application of metagenomics to engineered systems associated with extractive resource sectors.

Keywords: nitrifier denitrification, nitrogen cycle, oil sands, tailings deposits, shotgun metagenomics 


\section{INTRODUCTION}

The biogeochemical nitrogen cycle involves many microbiallycatalyzed forward and reverse redox reactions that interconvert nitrate, nitrite, ammonia, nitric acid, nitrous oxide, and dinitrogen species. Over the last decade, culture-independent surveys for functional marker genes of ammonia oxidation such as ammonia monooxygenase (amo) have enabled identification of the potential for nitrification within microbial communities and in specific taxa previously unknown to nitrify. Further, metagenome-assembled genomes can reveal novel $\mathrm{N}$ metabolic pathways; for example, the complete ammonia oxidation (commamox) pathway able to oxidize ammonia to nitrate (Daims et al., 2015; van Kessel et al., 2015).

Microbial nitrification and denitrification have many contrastive aspects, i.e., nitrification is typically conducted by obligately aerobic chemolithoautotrophs, while denitrification is driven by anaerobic heterotrophs (Kuypers et al., 2018 and references therein). The distribution of these metabolic pathways may overlap spatially in environments where the oxic/anoxic boundary varies through time. Denitrification via autotrophic ammonia-oxidizing bacteria (AOB) (Poth and Focht, 1985; Shaw et al., 2006), as well as non-energy-generating ammonia oxidation coupled to denitrification via heterotrophs (heterotrophic AOB) (Kampschreur et al., 2009) can co-occur at low oxygen concentrations. An oxic/anoxic interface is thus an enticing environment to study the microbial ecology driving elusive N cycles (Paerl and Pinckney, 1996; Brune et al., 2000), where microorganisms may dynamically switch the direction of nitrogen compound redox transformations. Although previous culture-independent surveys indicate the ubiquitous existence of aerobic nitrifiers in natural environments, they rarely dominate communities, and often face competition for ammonia and oxygen with heterotrophs (Geets et al., 2006). However, they do succeed in ammonium-rich, aerated, and organic matter-limited conditions found in engineered systems such as wastewater treatment systems (Dionisi et al., 2002; Kuypers et al., 2018). Many recently discovered nitrifying bacteria have been found in anthropogenically-impacted environments. Anaerobic ammonia-oxidizing (anammox) bacteria were discovered in a wastewater treatment system (Jetten et al., 1998), the first isolated ammonia-oxidizing archaea (AOA) Nitrosopumilus spp. was isolated from a marine aquarium tank (Könneke et al., 2005) and the comammox Nitrospira spp. was isolated from a deep oil exploration well (Daims et al., 2015). Thus, the specific targeting of anthropogenic, ammonia-rich environments may reveal novel nitrifying players that may also be present in natural environments as members of the rare biosphere.

Unexpected microbial communities have been found in mining-impacted environments (Thavamani et al., 2017), where organisms may adapt complex life cycles, specialized nutrient uptake mechanisms and metabolic activities. Our research has focused on an engineered pit lake in the Athabasca oil sands region of north-eastern Alberta (Canada), where geochemical results evidence microbial nitrification occurring in the water cap of this aquatic mine reclamation landform (Risacher et al., 2018). Base Mine Lake (Syncrude Canada; Fort McMurray, AB,
Canada) is the first full-scale demonstration of water capped tailings reclamation technology and was commissioned in 2012 as a demonstration of oil sands pit lakes (Dompierre et al., 2016). At commissioning, Base Mine Lake comprised ca. $45 \mathrm{~m}$ depth of fluid fine tailings (FFT) covered with an approximately $8 \mathrm{~m}$ freshwater and tailing porewater release cap. Previous findings showed a strong negative correlation between concentrations of water cap oxygen and concentrations of dissolved aqueous methane and ammonia, mobilized from the underlying FFT during summer stratification (Risacher et al., 2018). Thus, a trend of decreasing oxygen and increasing methane and ammonia concentrations with depth occurs within the water cap. However, methane was largely extinguished within the stratified lower hypolimnetic region of Base Mine Lake, while ammonia was detectable throughout the water cap, extending the possibility of nitrification higher up into the water cap region coincident with higher oxygen concentrations (Risacher et al., 2018). Further, the bulk organic carbon in this system is highly complex and less aerobically-biodegradable (Foght et al., 2017). Thus, despite relatively high DOC values ( $\sim 40 \mathrm{mg} / \mathrm{L}$; Syncrude Canada Ltd., 2017), Base Mine Lake is a potential hotspot for microbial nitrification, as the constant supply of ammonia and limited labile organic matter may enable nitrifying microorganisms to outcompete copiotrophs.

We sampled Base Mine Lake microbial communities during mid-summer of 2015 and 2016 to identify the microorganisms involved in nitrogen cycle within this engineered system. $16 \mathrm{~S}$ rRNA gene amplicon analysis was coupled with genomeresolved metagenomics to survey community compositions and to identify and characterize the nitrifiers present at both spatial and temporal scales. Determination of depth dependent water cap associated microbial community structure and function was complemented by geochemical characterization from the surface to the underlying FFT.

\section{MATERIALS AND METHODS}

\section{Site Description}

Base Mine Lake $\left(57^{\circ} 0^{\prime} 38.88^{\prime \prime} \mathrm{N}, 111^{\circ} 37^{\prime} 22.44^{\prime \prime} \mathrm{W}\right)$ is a $7.8 \mathrm{~km}^{2}$ engineered lake (Figure 1A) located $40 \mathrm{~km}$ north of Fort McMurray, Alberta, Canada. Tailings waste from extraction and processing of bitumen was pumped into a mined out pit from 1995 until 2012 (Dompierre et al., 2016; Foght et al., 2017), and the solids allowed to settle out, forming semi-consolidated FFT. FFT is composed of $50-60 \mathrm{wt} \%$ solids (clays, silts, and sands), containing ca. 1-5\% residual bitumen (Chalaturnyk et al., 2002; Dompierre et al., 2016). In December 2012, FFT inputs ceased and Base Mine Lake was commissioned as the first water-capped tailings technology demonstration reclamation project. Typical oil sands tailings ponds are anoxic within the first meter of water depth, driven by oxidation of hydrogen sulfide $\left(\Sigma \mathrm{H}_{2} \mathrm{~S}\right)$, methane $\left(\mathrm{CH}_{4}\right)$, and ammonia $\left(\mathrm{NH}_{4}{ }^{+}\right)$generated by anaerobic microbial activity (Foght et al., 2017). Base Mine Lake has a deeper water cap $(\sim 10 \mathrm{~m})$ relative to the typical $<5 \mathrm{~m}$ depth water cap in tailings ponds (Figure 1B), to increase the distance between FFT mobilized reductants such as methane, hydrogen sulfide 


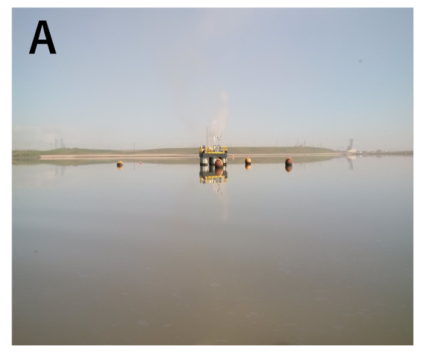

C

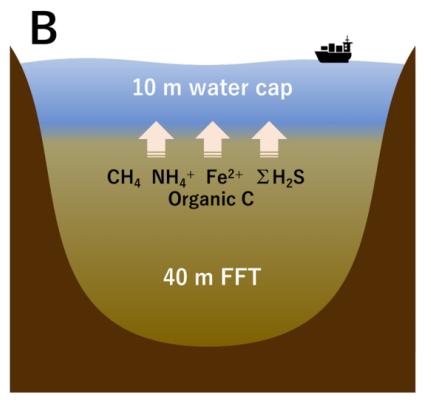

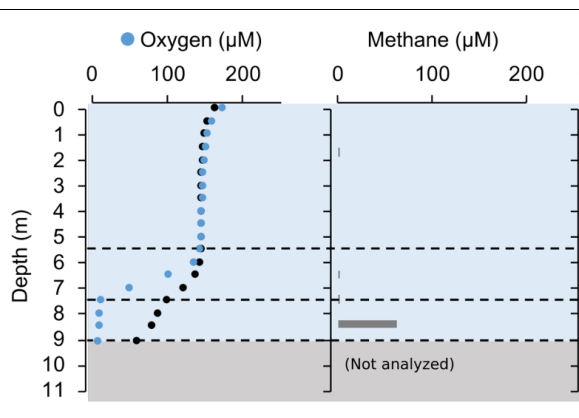

$N$ species $(\mu \mathrm{M})$

Aug 2015

Aug 2016

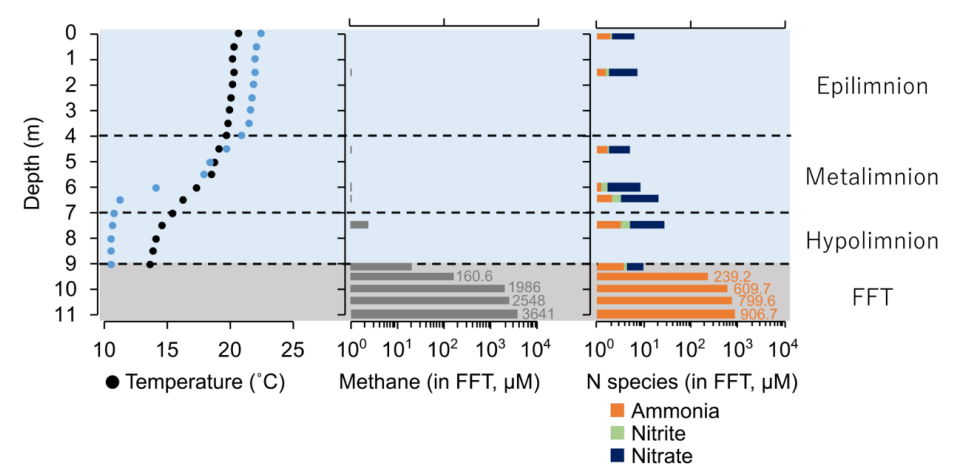

FIGURE 1 | (A) Base mine lake identifying the sampling platform where samples were collected (August 2016). (B) Cross-section model of Base Mine Lake showing main reductants released from the $\sim 40 \mathrm{~m}$ layer of fluid fine tailings (FFT). (C) Base Mine Lake physicochemical and geochemical water cap and shallow (2 meter) of underlying FFT profiles for August 2015 and 2016. Dissolved oxygen concentration $(\mu \mathrm{M})$ and temperature $\left({ }^{\circ} \mathrm{C}\right)$ in the left column, dissolved aqueous methane concentration $(\mu \mathrm{M})$ in the center column, and concentrations of three $\mathrm{N}$ redox species (ammonia, nitrite and nitrate; $\mu \mathrm{M}$ ) in the right column. Nitrogen species concentrations for 2015 were obtained from Syncrude's Base Mine Lake monitoring program (depths 0, 2, 4, 6, 8, 9 m) collected on August 10th, 2015. Dissolved aqueous methane and ammonia concentrations in the FFT were measured on August 5th 2015 and August 13 th 2016.

and ammonia from the upper water cap. This depth separation increases the likelihood that a stable oxic zone will remain within the upper water column to sustain macrofauna; a criterion for success of this reclamation technology.

\section{Physicochemical Profiling, Sample Collection, and Chemical Analyses for Base Mine Lake}

Water cap physico chemical profiling and sampling were conducted by boat during mid-summer stratification in 2015 and 2016 (August 18-20th and August 2-5th respectively), as a part of the larger study by Risacher et al. (2018; June-August 2015 and May-September 2016). Temperature, $\mathrm{pH}$, dissolved oxygen, and conductivity measurements were conducted using a YSI Professional Plus 6-Series Probe (Xylem, Rye Brook, NY, United States) at 0.5-1.0 m intervals from surface to the FFT-water interface (approximately $9.0 \mathrm{~m}$ in 2015 and $9.3 \mathrm{~m}$ in 2016, following consolidation of the FFT). Water samples were collected using a $6.2 \mathrm{~L}$ Van Dorn bottle sampler (Waster Mark, Forestry Supplies, Jackson, MS, United States) from each thermally stratified region, i.e., epilimnion, metalimnion and hypolimnion, as identified by the physicochemical profile (4 depths in Aug 2015 and 7 depths in Aug 2016 respectively, Figure 1C). Samples for dissolved aqueous $\mathrm{CH}_{4}, \Sigma \mathrm{H}_{2} \mathrm{~S}, \mathrm{Fe}^{2+}$, and nitrogen redox species $\left(\mathrm{NO}_{3}{ }^{-}, \mathrm{NO}_{2}{ }^{-}\right.$, and $\mathrm{NH}_{4}{ }^{+}$) as well as $\mathrm{SO}_{4}{ }^{2-}$, were analyzed using a $\mathrm{HACH}$ portable spectrophotometer (DR/2800, HACH, Loveland, CO, United States) as previously described by Risacher et al. (2018). At the same depths, ca. 1.5 L water was collected for microbial DNA extraction and filtered on board (see details below). Total- and dissolved organic carbon (TOC/DOC) samples were collected into the carbon-free glass bottles and stored at $-20^{\circ} \mathrm{C}$. Samples were analyzed using Total Organic Carbon Analyzer TOC$\mathrm{L}_{C P H / C P N}$ (Shimadzu, Japan; DOC was determined after passing samples through $0.45 \mu \mathrm{m}$ glass fiber filters).

Physicochemical profiling and sampling of the FFT were carried out on August 5th, 2015 and August 13th, 2016 at the location as the water cap sampling campaigns by Risacher et al. (2018). The FFT samples were collected into $250 \mathrm{~mL}$ high density polyethylene bottles using a custom-built fixed interval sampler for collecting FFT at $0.10 \mathrm{~m}$ vertical spacing over the $2 \mathrm{~m}$ interval positioned immediately below the FFTwater interface. Additional details on the design and operation of this sampler are provided by Dompierre et al. (2017). Temperature and $\mathrm{pH}$ were measured immediately on the boat using a combined electrode (model 8172BNWP; Thermo Fisher Scientific, Waltham, MA, United States). The FFT samples were placed on ice and transferred to an on-site laboratory within $6 \mathrm{~h}$. Sub-samples for microbial DNA extraction were collected into sterile $50 \mathrm{~mL}$ centrifuge tubes and stored at $-20^{\circ} \mathrm{C}$. The remaining FFT samples were refrigerated $\left(4^{\circ} \mathrm{C}\right)$ for up to $12 \mathrm{~h}$ until analysis. Pore water was extracted by centrifugation $(8500 \times g, 30 \mathrm{~min})$ and passed through 
$0.45 \mu \mathrm{m}$ PES syringe filter membranes. Electrical conductivity was measured using a conductivity probe (model $013005 \mathrm{MD}$; Thermo Fisher Scientific). Dissolved $\mathrm{\Sigma H}_{2} \mathrm{~S}$ and $\mathrm{NH}_{4}{ }^{+}$were quantified using the same methods described above for water cap sample analyses. Samples for dissolved $\mathrm{SO}_{4}{ }^{2-}, \mathrm{NO}_{3}{ }^{-}$, and $\mathrm{NO}_{2}{ }^{-}$were transferred to HDPE bottles and refrigerated $\left(4^{\circ} \mathrm{C}\right)$ until analysis by ion chromatography (Dionex ICS-2000, Thermo Fisher Scientific, Sunnyvale, CA, United States). Sub-samples for dissolved methane analysis were collected on the sampling boat immediately following collection of the FFT samples. For each dissolved methane sample, approximately $60 \mathrm{~g}$ of FFT was transferred into a $120 \mathrm{~mL}$ amber glass serum bottle, which was immediately crimp-sealed using a butyl rubber stopper. The samples were frozen to prevent ongoing methane production and subsequently thawed and placed on a shaker table at ambient temperature for $24 \mathrm{~h}$ before analysis. The headspace gas concentrations were quantified on a gas chromatograph fitted with a thermal conductivity detector (490 micro GC, Agilent Technologies, Santa Clara, CA, United States). Dissolved gas concentrations were determined using gravimetric water contents and established partitioning coefficients.

\section{Microbial DNA Extraction}

Water cap microbial cells were collected by filtering $\sim 1.5 \mathrm{~L}$ water through $0.22 \mu \mathrm{m}$ Rapid-Flow sterile disposable filters (Thermo Fisher Scientific) and stored at $-20^{\circ} \mathrm{C}$ until the DNA extraction. Genomic DNA was extracted from the water cap filter samples using the DNeasy PowerWater DNA Isolation Kit (Qiagen, Hilden, Germany) and stored at $-20^{\circ} \mathrm{C}$ for downstream analyses. A total of 18 samples were analyzed using microbial $16 \mathrm{~S}$ rRNA gene amplicon sequencing (V4 region), and a subset of 11 were sequenced for metagenomics analyses (shotgun sequencing, Supplementary Table S1). Genomic DNA was extracted from ca. $0.5 \mathrm{~g}$ of each FFT sample using the FastDNA Spin Kit for Soil (MP Biomedical, Irvine, CA, United States), and stored at $-20^{\circ} \mathrm{C}$. The samples were homogenized in the cell disruption step to enhance extraction efficiency (Fast Prep 120, Thermo Scientific Savant, Waltham, MS, United States). The manufacturer protocol was modified to increase DNA quality and quantity. These modifications included repeating: (i) the cell disruption step two times and pooling resulting product before adding the binding matrix solution; (ii) the ethanol wash step three times to enhance removal of organics; and (iii) the elution step two times with DNA-free water to obtain $100-150 \mu \mathrm{L}$ of DNA solution. DNA yield was confirmed with a Qubit 2.0 Fluorometer (Thermo Fisher Scientific) using a Qubit High Sensitivity dsDNA Assay Kit (Thermo Fisher Scientific) and DNA quality was assessed using an Epoch Microplate Spectrophotometer with Take3 plate (BioTek, Winooski, VT, United States).

\section{Microbial 16S rRNA Gene Amplicon Sequencing}

Identical primers and variable region were used to characterize the microbial community structure in water and FFT genomic DNA samples; the high-throughput amplicon sequencing protocol is briefly summarized as follows. The variable region
4 of the $16 \mathrm{~S}$ rRNA gene was amplified by PCR from the purified DNA, using Illumina adapted primers (Bartram et al., 2011) following standard protocols of the Earth Microbiome Project (Caporaso et al., 2011, 2012). The primer set 515f (5'-GTGYCAGCMGCCGCGGTAA-3') and 806r (5'GGACTACNVGGGTWTCTAAT- $3^{\prime}$ ) was used to amplify the $\mathrm{V} 4$ region of the bacterial and archaeal 16S rRNA gene (Bates et al., 2010). The PCR reaction protocol was as follows: $50 \mathrm{ng}$ of DNA as template, initial denaturing at $98^{\circ} \mathrm{C}$ for $5 \mathrm{~min}, 35$ cycles of denaturing at $98^{\circ} \mathrm{C}$ for $30 \mathrm{~s}$, annealing at $50^{\circ} \mathrm{C}$ for $30 \mathrm{~s}$ and extension at $72^{\circ} \mathrm{C}$ for $30 \mathrm{~s}$, followed by final extension at $72^{\circ} \mathrm{C}$ for $10 \mathrm{~min}$ (Bates et al., 2010). For the water cap microbial community, PCR products were checked by gel electrophoresis and positive amplicons were sequenced using the Illumina MiSeq platform at Farncombe Metagenomics Facility at McMaster University (Hamilton, Canada). All amplicons were normalized using the SequalPrep normalization kit (Thermo Fisher Scientific) and sequenced with the Illumina MiSeq platform. Sequence reads were filtered and trimmed using Cutadapt (minimum quality score of 30 and a minimum read length 100 bp; Martin, 2011). Sequence variants were then resolved from the trimmed raw reads using a sample inference pipeline DADA2 and reported as sequence variants (Callahan et al., 2016). Sequence variant tables were merged to combine all information from separate Illumina runs. Bimeras were removed along with sequences identified as mitochondria or chloroplasts, and taxonomy was assigned using the SILVA database version 132. Sequences belonging to Eukaryota, chloroplasts and mitochondria were removed. For the FFT samples, amplicon sequencing was conducted using the Illumina MiSeq platform at the University of Calgary. The same $\mathrm{V} 4$ region of bacterial and archaeal 16S rRNA gene as the water cap samples (515f/806r) was amplified and sequenced. The PCR reactions were as follows: initial denaturing at $94^{\circ} \mathrm{C}$ for $3 \mathrm{~min}$, 24 cycles of denaturing at $94^{\circ} \mathrm{C}$ for $45 \mathrm{~s}$, annealing at $50^{\circ} \mathrm{C}$ for $60 \mathrm{~s}$ and extension at $72^{\circ} \mathrm{C}$ for $90 \mathrm{~s}$, and final extension at $72^{\circ} \mathrm{C}$ for $10 \mathrm{~min}$. Sequence reads were processed using the mothur bioinformatics software package MiSeq standard operating procedure (Schloss et al., 2009; Kozich et al., 2013). Chimeras were identified and removed using the VSEARCH algorithm (Rognes et al., 2016). Taxonomy was assigned using the SILVA database version 132 .

\section{Water Cap Metagenomic Sequencing, de novo Assembly, and Genome Binning}

Library construction and sequencing were performed at the Farncombe Metagenomics Facility at McMaster University (Hamilton, Canada). Microbial DNA samples (up to $1 \mu \mathrm{g}$ ) were fragmented using the Covaris S220 Ultrasonicator (Covaris, Woburn, MA, United States) in snap-cap microtubes. Parameters for 500 bp shearing with $50 \mu \mathrm{L}$ input were: $175 \mathrm{~W}$ PIP, 5\% duty factor, $200 \mathrm{cpb}, 35 \mathrm{~s}$. Dual-indexed shotgun libraries were prepared with the NEBNext Ultra DNA Library Prep Kit for Illumina (New England Biolabs, Beverly, MA, United States). The libraries were quantitated by quantitative PCR, using primers complementary to the distal ends of the Illumina adaptors. 
Illumina's PhiX v3 control library was used to generate a standard curve. Quantified libraries were pooled in equimolar amounts and sequenced using the Illumina HiSeq 1500 platform (Rapid v2 chemistry with onboard cluster generation, 151 bp pairedend reads). Raw data were processed with HCS v2.2.58 (RTA v1.18.64). File conversion and demultiplexing were performed with CASAVA v1.8.2 allowing 1 mismatch in the indexes. Raw reads were filtered to remove adapters and PhiX/Illumina sequencing contaminants, and then trimmed using the sickle software (Joshi and Fass, 2011) to remove low quality bases/reads. Quality reads from all samples was individually assembled using IDBA_UD (Peng et al., 2012) with kmer-set of " $20,40,60$, $80,100,120,140$." The protein-coding genes were predicted from those scaffolds with a minimum length of 1000 bp using Prodigal (Hyatt et al., 2010), and annotated by searched using Usearch (Edgar, 2010) against the KEGG, UniRef100 and Uniprot databases. Also, 16S rRNA and tRNA genes were predicted from those scaffolds with HMM search (Brown et al., 2015) and tRNAscanSE (Lowe and Eddy, 1997), respectively. For coverage calculation, the corresponding quality reads were mapped to the scaffolds using Bowtie2 (Langmead and Salzberg, 2012) with default parameters, then the coverage was calculated as the total mapped bases divided the length of the scaffold. Genome binning was performed using MetaBAT (Kang et al., 2015) based on the coverage and tetranucleotide frequency (TNF) of each scaffold with default parameters. The initial genome bins obtained from MetaBAT were subsequently imported to ggKbase ${ }^{1}$, and manually modified based on taxonomic information of genes on scaffolds.

\section{Microbial Growth Rates (dRep and iRep)}

All modified genome bins were evaluated by CheckM for genome completeness and contaminations (Parks et al., 2015). Representative genome bins were selected with dRep for genomes with a completeness $\geq 50 \%$ and contamination $\leq 10 \%$ (Olm et al., 2017). The growth rate of microorganisms in endemic Base Mine Lake communities was assessed using the index of replication (iRep) which determines microbial growth activity based on sequencing read coverage pattern (Brown et al., 2016) within representative bins.

\section{Phylogenetic Analyses}

Phylogenetic trees of the 16S rRNA gene and selected functional genes, both derived from the shotgun sequencing data, were constructed based on the maximum-likelihood method using MEGA (v7.0.26) (Kumar et al., 2016). Reference sequences for the $16 \mathrm{~S}$ rRNA gene and functional genes of different microorganisms were obtained using the SILVA (version 132) and IMG databases, respectively. Relevant nucleic acid or amino acid sequences were aligned using ClustalW in MEGA and the phylogenetic trees were created using Tamura-Nei model with 1000 bootstrap iterations.

\section{DNA Sequence Accession Numbers}

The water cap microbial 16S rRNA gene amplicon sequences, as well as microbial genomes obtained from metagenomics are deposited at NCBI under BioProject PRJNA552483. The

${ }^{1}$ https://ggkbase.berkeley.edu/
FFT microbial 16S rRNA gene sequences were deposited in the European Nucleotide Archive; study accession number PRJEB32633.

\section{RESULTS}

\section{Physico- and Geochemistry}

The physicochemical and geochemical features of water cap and FFT samples from August of 2015 and 2016 are summarized in Supplementary Table S1. The water cap was thermally stratified with circumneutral $\mathrm{pH}$. Oxygen concentrations decreased with depth, reaching $<3 \%$ saturation at the FFT-water interface (9.0 m; Figure 1C and Supplementary Table S1), and becoming euxinic within the FFT. The highest level of dissolved aqueous methane concentration $(\sim 70 \mu \mathrm{M})$ in the water cap was detected at the lower hypolimnetic zone. In the underlying FFT, methane was present at concentrations up to two orders of magnitude higher, reaching $3.6 \mathrm{mM}$ at $\sim 2 \mathrm{~m}$ below the FFT-water interface (Supplementary Table S1). Nitrate, nitrite and ammonia were detectable throughout the water cap in both years, which were with higher concentrations in 2015 compared to 2016. FFT had higher ammonia concentrations $(700 \sim 1100 \mu \mathrm{M})$ than the water cap, while nitrite was non-detectable and nitrate was barely detected $(\sim 1.3 \mu \mathrm{M})$. Sulfate concentrations were high and homogeneous in the water cap for both summers (1.5-2.6 mM), while dissolved $\Sigma \mathrm{H}_{2} \mathrm{~S}$ was only detected at the anoxic FFTwater interface $(\sim 1.24 \mu \mathrm{M})$ and in the underlying, shallow (from the FFT water interface to $2 \mathrm{~m}$ below) FFT zone $(\sim 2.56 \mu \mathrm{M}$; Supplementary Table S1). TOC/DOC concentrations showed no evident depth dependence, ranging between $303 \sim 458 \mathrm{mg} / \mathrm{L}$ and 43 $58 \mathrm{mg} / \mathrm{L}$ respectively (Supplementary Table S1).

\section{Microbial Community Analyses}

Relative sequence variant abundances of each microbial class and order sequenced from the Base Mine Lake water cap as well as from three depths within the underlying FFT layer are summarized in Figure $\mathbf{2}$ and Supplementary Table S2. The common AOB Nitrosomonadaceae (Betaproteobacteriales; the SILVA database version 132 implements the Genome Taxonomy Database taxonomy system, which proposes that the class Betaproteobacteria is reclassified as an order within the class Gammaproteobacteria; Parks et al., 2018) was detected in all water cap samples collected from both summers, although in low abundance $(<1 \%)$, with the highest abundances associated with the upper, more oxygenated water cap regions (Figure 3 and Supplementary Table S2). Intriguingly, an unclassified gammaproteobacterial group "MBAE14" was the most abundant microbial order detected in the low oxygen ( $<5 \%$ saturation) hypolimnetic and FFT-water interface zones in $2016(20.5 \%$ at $7.5 \mathrm{~m}, 27.8 \%$ at $9.3 \mathrm{~m})$, and ranked as the second most abundant order at $8.5 \mathrm{~m}$ in the water cap in 2015 (19.5\%), with Betaproteobacteriales the most dominant group (20.1\%). However, it was not detected in the underlying FFT (Figures 2, 3 and Supplementary Table S2). The known methanotroph Methylococcales was present throughout the water cap with higher abundance in the 


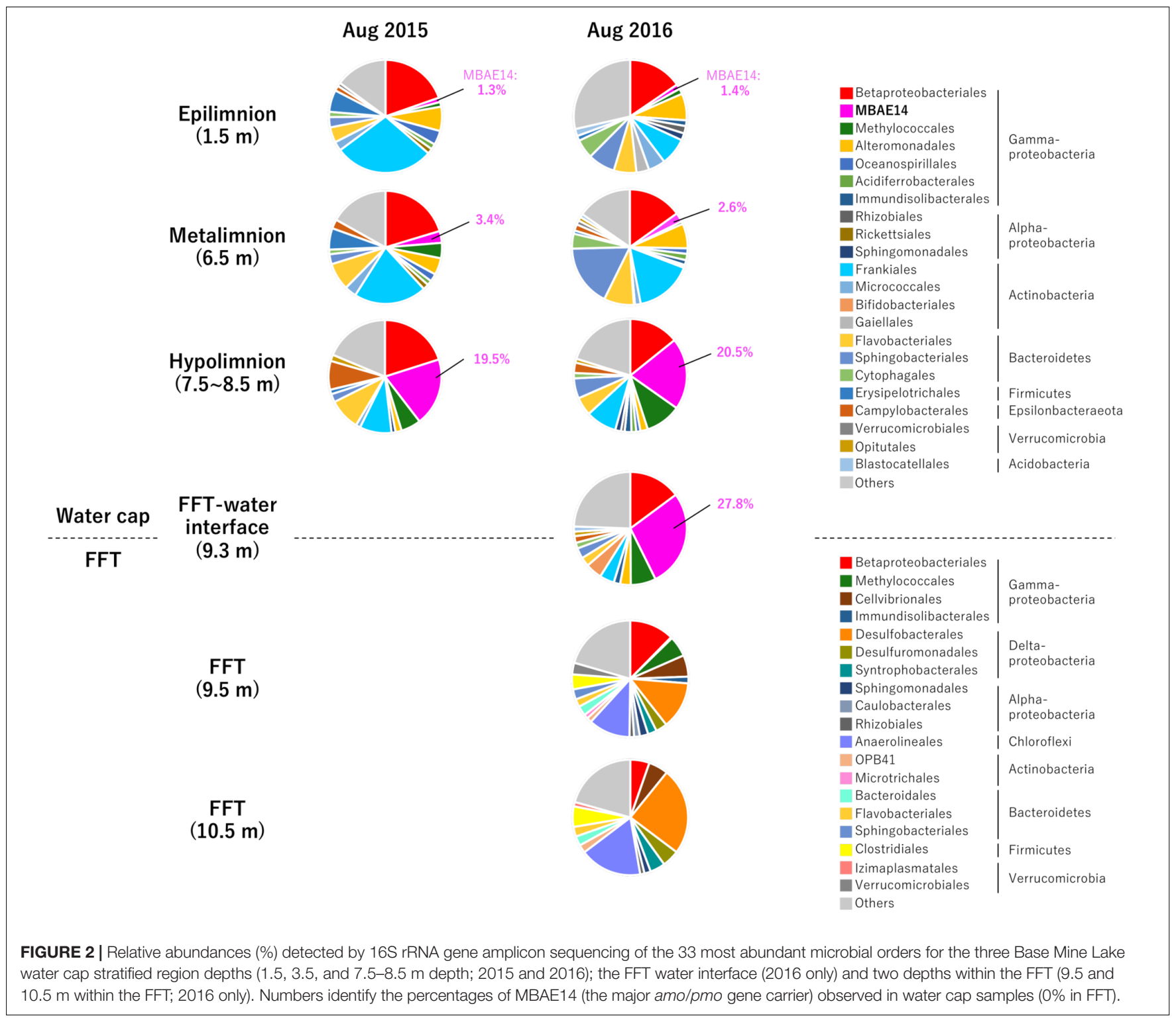

hypolimnetic zones (up to 10\%), as well as right below the FFT-water interface $(5.7 \%)$ but was not detected deeper within the FFT. Frankiales $(<29 \%)$, Sphingobacteriales $(<17 \%)$, and Flavobacteriales $(<9 \%)$ dominated the oxic portion of the water cap, while Desulfobacterales $(<24 \%)$ and Anaerolineales $(<17 \%)$ dominated the anoxic FFT zone (Figure 2 and Supplementary Table S2).

\section{Metagenomics Survey for Microbial Functional Genes}

Ammonia monooxygenase (amoABC) and particulate methane monooxygenase ( $p m o \mathrm{ABC}$ ) genes were detected throughout the entire water column, revealing widespread genomic metabolic potential for nitrification and methanotrophy. Subsequent genome-reconstruction showed that these amo/pmo genes were encoded in genomes of the unclassified gammaproteobacterial group MBAE14 observed to be highly abundant in the hypolimnetic and the FFT-water interface zones (Figure 2), as were the methanotroph Methylococcales family (Methylobacter, Methylovulum, Methylocaldum), and an unclassified Burkholderiaceae (full 16S rRNA gene sequence was not obtained). Further, genes for hydroxylamine oxidoreductase (hao), the marker gene for the second step of ammoniaoxidation (oxidizing hydroxylamine to nitrite), was also detected in all analyzed metagenomic samples, but associated only with the MBAE14 group genome. Partial amo and hao genes from genomes of a typical AOB Nitrosomonadaceae (Betaproteobacteriales) were detected in the metalimnetic and hypolimnetic water cap samples for both summers, but with very low relative abundances. Genes for nitrite oxidoreductase ( $n x r \mathrm{AB}$, nitrite oxidation) were detected in a genome of an unclassified Chloroflexi group "JG30-KF-CM66," and that genome was detectable in all analyzed samples. 


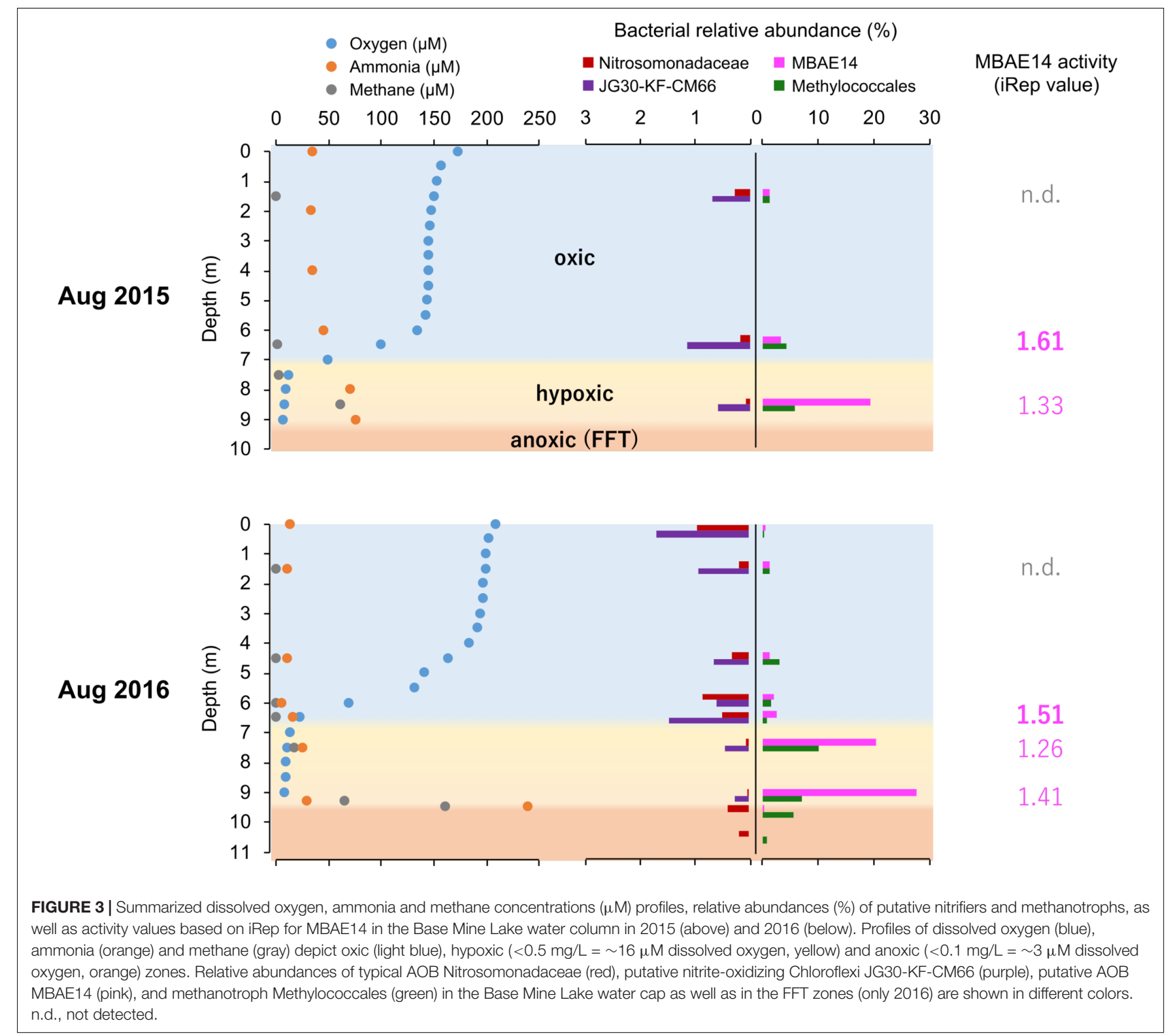

Collectively, these results indicate that nitrification within the Base Mine Lake water cap is likely associated with a novel unclassified gammaproteobacterial group MBAE14, aerobic AOB Nitrosomonadaceae, the nitrite-oxidizing Chloroflexi, as well as potentially Methylococcales and uncertain Burkholderiaceae though the latter are more likely methanotrophs (no hao genes detected).

\section{Replication Rates of Potential Nitrifiers in Water Column}

The iRep analyses (replication rates, i.e., "activity") were retrieved for the potential nitrifiers in the Base Mine Lake water cap, when a given genome has a minimum coverage of $5 \mathrm{X}$ in the sample (methods). Thus, iRep values for the amo/pmo carriers MBAE14 and Methylococcales (Methylobacter and another unassigned species) are only reported for the metalimnion and hypolimnion of the water cap, whereas the activity of Nitrosomonadaceae as well as Chloroflexi was not possible to determine from all samples. MBAE14 activity was relatively high in the metalimnion (1.61 in 2015 and 1.51 in 2016) compared to the hypolimnion (1.33 in 2015, 1.26-1.41 in 2016; Figure 3), while Methylococcales showed an opposite trend (1.82 and 1.45 in the hypolimnion for 2015 and 2016 respectively; 1.64 in the metalimnion in 2015).

\section{Genomic Characterization for the Gammaproteobacterial Group MBAE14}

A full length 16S rRNA gene (1535 bp) was identified in the genome of MBAE14. From phylogenetic analyses, the MBAE14 organism found in Base Mine Lake ("BML MBAE14") showed low 16S rRNA gene sequence homologies 
$(<94.8 \%)$ and taxonomically the organism is located in a unclassified, uncultured gammaproteobacterial clade MBAE14 (SILVA database 132; Figure 4 and Table 1). The closest cultured bacterial groups to MBAE14 are represented by Oceanospirillales (Oleiphilus spp., Family Nitrincolaceae, Marinomonas spp., Family Saccharospirillaceae) and Marinobacter spp. (Alteromonadales).

A genome $(96.11 \%$ completeness, $3.15 \mathrm{Mbp})$ of the BML MBAE14 was reconstructed from metagenomic data (information is summarized in Supplementary Table S3). The BML MBAE14 genome encodes gene clusters including amo $\mathrm{ABC}$ (EC 1.14.99.39) and hao (EC 1.7.2.6) for nitrification (and potentially methanotrophy), which is widely conserved in other known $\mathrm{AOB}$ and comammox (Figure 5A). These amo and hao genes were distantly related to those of the known autotrophic AOB, comammox, AOA as well as methanotrophs (Figures 5B,C). Interestingly, BML MBAE14 also possesses genes for the whole pathway of denitrification $\left(\mathrm{NO}_{3}{ }^{-} / \mathrm{NO}_{2}{ }^{-}\right.$

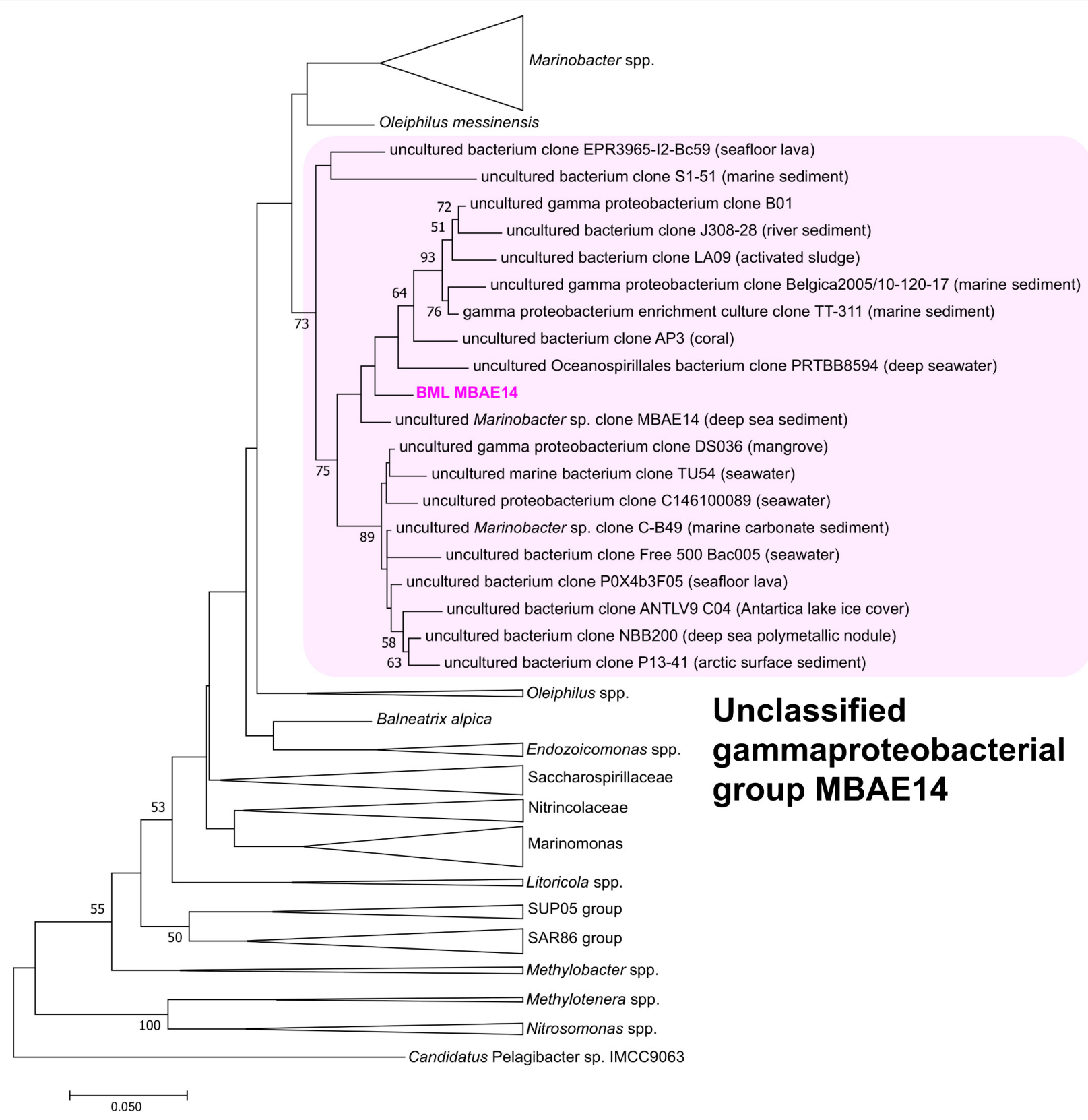

FIGURE 4 | Maximum-likelihood phylogenetic tree of 16S rRNA gene of the BML MBAE14 and phylogenetically-related bacterial groups. The tree was rooted with 16S rRNA gene of Candidatus Pelagibacter sp. IMCC9063 (SAR11 group, Alphaproteobacteria). The tree was created with 1000 bootstrap iteration (values below $50 \%$ are not reported). The origins of each uncultured bacterial clone belonging to the MBAE14 group are reported in parentheses. 
TABLE 1 | Characterization of the potential metabolic capabilities for BML MBAE14 compared to phylogenetically-related bacterial groups as well as known methanotrophic and nitrifying bacterial/archaeal groups.

\begin{tabular}{|c|c|c|c|c|c|c|c|c|c|c|c|c|c|c|c|}
\hline \multirow[t]{3}{*}{ Organism } & \multicolumn{3}{|c|}{ Taxonomy } & \multirow{3}{*}{$\begin{array}{l}\% \text { homology } \\
\text { with BML } \\
\text { MBAE14 }\end{array}$} & \multirow{3}{*}{ Group description } & \multicolumn{10}{|c|}{ Presence of functional genes (\# in IMG genome database) } \\
\hline & \multirow[t]{2}{*}{ Class } & \multirow[t]{2}{*}{ Order } & \multirow[t]{2}{*}{ Family } & & & \multicolumn{3}{|c|}{ Nitirification } & \multicolumn{5}{|c|}{ Denitrification } & \multicolumn{2}{|c|}{$\mathrm{CO}_{2}$-fixation } \\
\hline & & & & & & $\begin{array}{l}\text { amo } \\
\text { (pmo) }\end{array}$ & hao & $\begin{array}{l}n \times r A / \\
n a r G\end{array}$ & napA & nirK & nirS & norB & nosZ & $\begin{array}{l}\text { Rubis } \\
\text { co }\end{array}$ & acl \\
\hline BML MBAE14 & Gammaproteobacteria & MBAE14 & & - & $\begin{array}{l}\text { Bacterium in } \\
\text { Base Mine Lake }\end{array}$ & + & + & + & - & + & - & + & + & - & - \\
\hline MBAE14 group & & & & $<94.8$ & $\begin{array}{l}\text { Uncultured } \\
\text { marine group }\end{array}$ & No genor & me avail & able in $\mathrm{d}$ & atabase & & & & & & \\
\hline Oleiphilus spp. & & Oceanospirillales & Oleiphilaceae & $<90.0$ & Marine heterotrophs & $0 / 29$ & $0 / 29$ & $13 / 29$ & $8 / 29$ & $0 / 29$ & $14 / 29$ & $13 / 29$ & $12 / 29$ & $0 / 29$ & $0 / 29$ \\
\hline Marinobacter spp. & & Alteromonadales & Marinobacteraceae & $<90.0$ & Marine heterotrophs & $0 / 85$ & $0 / 85$ & $60 / 85$ & $11 / 85$ & $7 / 85$ & $30 / 85$ & $55 / 85$ & $59 / 85$ & $0 / 85$ & $0 / 85$ \\
\hline Nitrincolaceae & & Oceanospirillales & & $<89.7$ & Marine heterotrophs & $0 / 29$ & $0 / 29$ & $8 / 29$ & $2 / 29$ & $1 / 29$ & $2 / 29$ & $8 / 29$ & $8 / 29$ & $3 / 29$ & $0 / 29$ \\
\hline Saccharospirillaceae & & & & $<89.6$ & Marine heterotrophs & $0 / 20$ & $0 / 20$ & $1 / 20$ & $5 / 20$ & $1 / 20$ & $1 / 20$ & $3 / 20$ & $3 / 20$ & $0 / 20$ & $0 / 20$ \\
\hline Marinomonas spp. & & & Marinomonadaceae & $<87.9$ & Marine heterotrophs & $0 / 26$ & $0 / 26$ & $0 / 26$ & $2 / 26$ & $0 / 26$ & $0 / 26$ & 0/26 & $0 / 26$ & $4 / 26$ & $0 / 26$ \\
\hline Pseudomonas stutzeri & & Pseudomonadales & Pseudomonadaceae & $<88.4$ & $\begin{array}{l}\text { Heterotrophic } \\
\text { AOB }\end{array}$ & 0/33* & $0 / 33^{*}$ & $25 / 33$ & $29 / 33$ & $12 / 33$ & $30 / 33$ & $29 / 33$ & $29 / 33$ & $1 / 33$ & $0 / 33$ \\
\hline Methylococcus spp. & & Methylococcales & Methylococcaceae & $<87.5$ & Type X Methanotrophs & $3 / 3$ & $3 / 3$ & $0 / 3$ & $0 / 3$ & $0 / 3$ & $0 / 3$ & $3 / 3$ & $0 / 3$ & $3 / 3$ & $0 / 3$ \\
\hline Methylobacter spp. & & & & $<87.3$ & Type I Methanotrophs & $18 / 18$ & $5 / 18$ & $10 / 18$ & $0 / 18$ & $7 / 18$ & $0 / 18$ & $5 / 18$ & $0 / 18$ & $0 / 18$ & $0 / 18$ \\
\hline Nitrosococcus spp. & & Nitrosococcales & Nitrosococcaceae & $<84.9$ & Autotrophic AOB & $7 / 7$ & $7 / 7$ & $0 / 7$ & $0 / 7$ & $6 / 7$ & $0 / 7$ & $7 / 7$ & $0 / 7$ & $6 / 7$ & $0 / 7$ \\
\hline Nitrosomonas spp. & & Betaproteobacteriales & Nitrosomonadaceae & $<80.9$ & Autotrophic AOB & $51 / 52$ & $47 / 52$ & $0 / 52$ & $0 / 52$ & $44 / 52$ & $0 / 52$ & $35 / 52$ & $0 / 52$ & $52 / 52$ & $0 / 49$ \\
\hline Nitrosospira spp. & & & & $<79.9$ & Autotrophic AOB & $31 / 31$ & $31 / 31$ & $0 / 31$ & $0 / 31$ & $28 / 31$ & $0 / 31$ & $14 / 31$ & $0 / 31$ & $31 / 31$ & $0 / 31$ \\
\hline Alcaligenes faecalis & & & Burkholderiaceae & $<78.9$ & $\begin{array}{l}\text { Heterotrophic } \\
\text { AOB }\end{array}$ & $0 / 9^{*}$ & $0 / 9^{*}$ & $0 / 9$ & 0/9 & $9 / 9$ & $0 / 9$ & $9 / 9$ & $9 / 9$ & $5 / 9$ & 0/9 \\
\hline $\begin{array}{l}\text { Paracoccus } \\
\text { pantotrophus }\end{array}$ & Alphaproteobacteria & Rhodobacterales & Rhodobacteraceae & $<77.1$ & $\begin{array}{l}\text { Heterotrophic } \\
\text { AOB }\end{array}$ & $0 / 5^{*}$ & $0 / 5^{*}$ & $5 / 5$ & $5 / 5$ & $0 / 5$ & $5 / 5$ & $5 / 5$ & $5 / 5$ & $5 / 5$ & $0 / 5$ \\
\hline $\begin{array}{l}\text { Nitrospirae } \\
\text { (comammox) }\end{array}$ & (Candidatus) Nitrospira & & & $<75$ & Comammox & $4 / 4$ & $4 / 4$ & $4 / 4$ & $1 / 4$ & $4 / 4$ & $2 / 4$ & $0 / 4$ & $0 / 4$ & $1 / 4$ & $4 / 4$ \\
\hline $\begin{array}{l}\text { Nitrosopumilus spp. } \\
\text { (Thaumarchaeota) }\end{array}$ & Nitrososphaeria & Nitrosopumilales & Nitrosopumilaceae & $<75$ & Autotrophic AOA & $4 / 9$ & $0 / 9$ & $0 / 9$ & $0 / 9$ & $4 / 9$ & $0 / 9$ & $0 / 9$ & 0/9 & 0/9 & 0/9 \\
\hline
\end{tabular}

Presence of functional genes is shown in gray (present in $>30 \%$ of the reference genomes of each bacterial group in IMG database; bold, $>50 \%$ ). *Putative genes (not homologous) and enzymes were previously sequenced or purified. amoA (pmoA), ammonia monooxygenase (ammonia $\rightarrow$ hydroxylamine) (methane $\rightarrow$ methanol); hao, hydroxylamine oxidoreductase (hydroxylamine $\rightarrow$ nitrite); nxrAlnarG, napA, nitrite oxidoreductase/nitrate reductase (nitrite $\longleftrightarrow$ nitrate); nirK, nirS, nitrite reductase (nitrite $\rightarrow$ nitric oxide); norB, nitric oxide reductase (nitric oxide $\rightarrow$ nitrous oxide); nosZ, nitrous oxide reductase (nitrous oxide $\rightarrow$ nitrogen); RubisCO, ribulose-biosphosphate carboxylase (key enzyme for $\mathrm{CO}_{2}$-fixation by Calvin-Benson-Bessham cycle); acl, ATP-citrate lyase (key enzyme for $\mathrm{CO}_{2}$-fixation by reductive TCA cycle). 


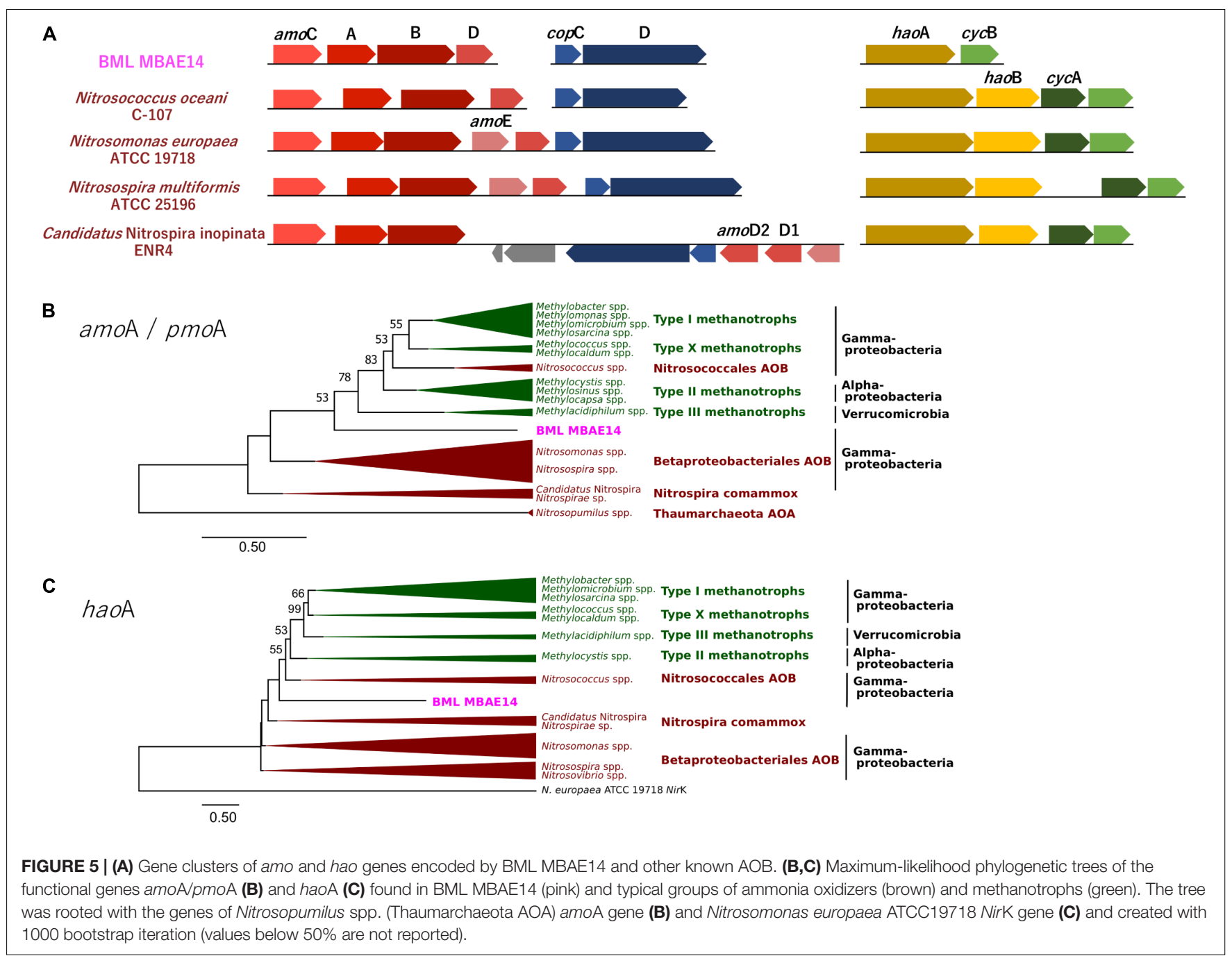

$\rightarrow \mathrm{NO} \rightarrow \mathrm{N}_{2} \mathrm{O} \rightarrow \mathrm{N}_{2}$ ) as well as a nitrate/nitrite transporter (Figure 6 and Table 1). The BML MBAE14 genome does not encode any known genes for $\mathrm{CO}_{2}$-fixation for autotrophic growth (such as Calvin-Benson-Bessham cycle, reductive TCA cycle and reductive acetyl-CoA pathway, Table 1). In addition, BML MBAE14 possesses gene sets related to glycolysis and fatty acid degradation, while encoding none of the functional genes for methanotrophic pathways (methanol $\rightarrow$ formaldehyde, carbon-fixation via RuMP cycle or serine cycle), suggesting they possess heterotrophic rather than methanotrophic capabilities.

\section{DISCUSSION}

\section{The Microbial Nitrogen Cycle Within a Manmade Oil Sands Mining Pit Lake}

Niches for aerobic microbial nitrification are created by the relative availabilities of ammonia, oxygen and organic matter. Autotrophic, aerobic nitrifiers can compete for ammonia and oxygen with heterotrophs in ammonia-rich and organic matterlimited environments (Kuypers et al., 2018). However, an adequate supply of ammonia typically relies on ammonification from organic matter mineralization coupled to nitrate/nitrite reduction, which requires high organic matter loads (Giblin et al., 2013). The Base Mine Lake water cap exhibits specific conditions of an ammonia-rich and labile organic matter-limited environment (Foght et al., 2017), creating a niche capable of supporting the novel potential AOB group MBAE14, in the hypolimnetic and the FFT-water interface zones (Figures 2, 3 and Supplementary Table S2). While the Base Mine Lake water cap is characterized as brackish (approximately $400 \mathrm{mg} / \mathrm{L}$ chloride; White and Liber, 2018), the bacterial groups related to BML MBAE14 (Oceanospirillales and Marinobacter spp.) were previously reported only in marine environments (Gauthier et al., 1992; Cappello and Yakimov, 2010; Satomi and Fujii, 2014). Furthermore, although BML MBAE14 and some related groups (Oceanospirillales and Marinobacter spp.) are potentially capable of denitrification, none of these groups carries functional genes for methanotrophy and nitrification (Table 1; IMG genome database). Some known $\mathrm{AOB}$ are also capable of reducing nitrite to nitric acid, but none of the currently identified $\mathrm{AOB}$ encodes the full denitrification process to dinitrogen as 


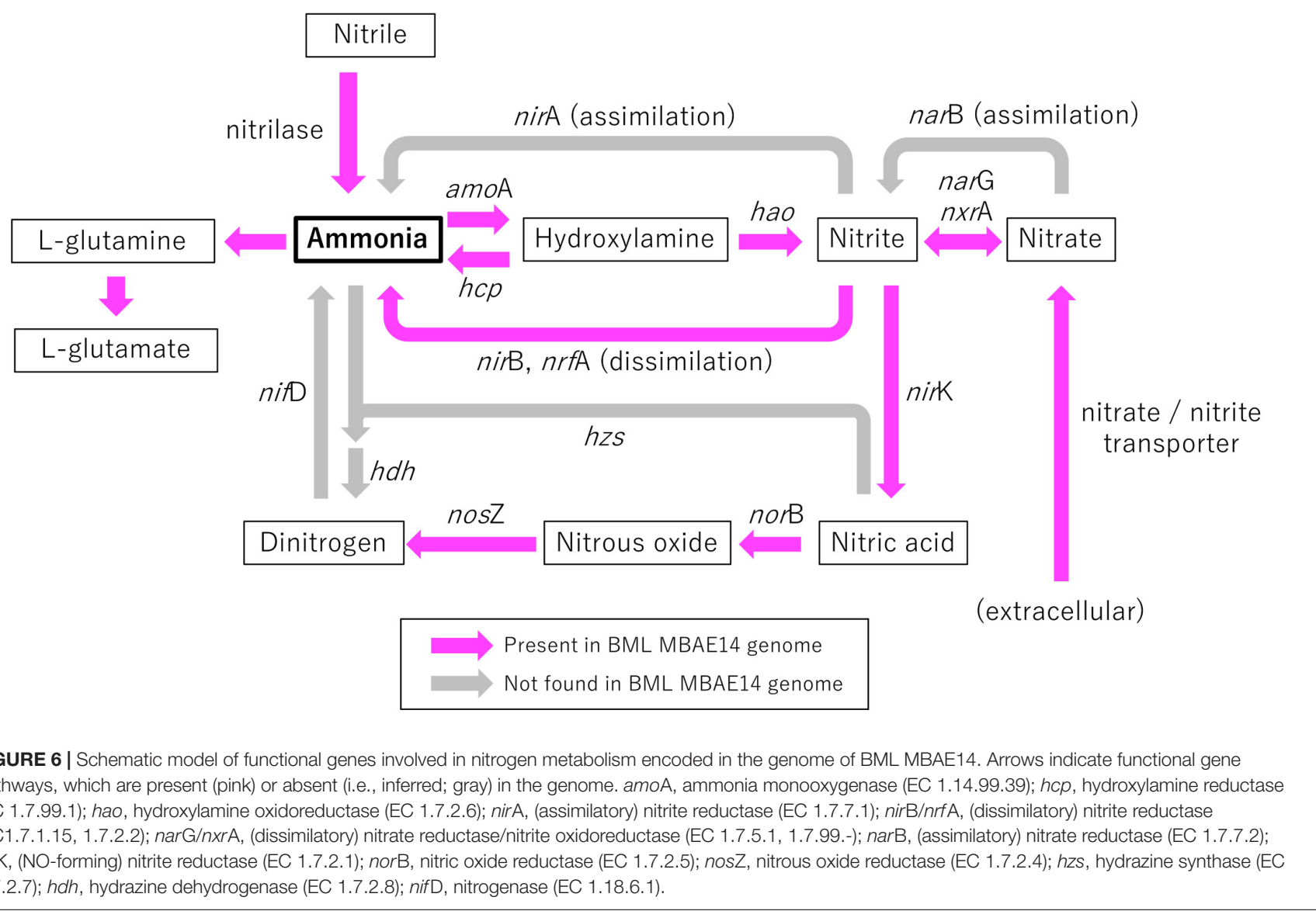

observed in BML MBAE14, Oleiphilus spp., and Marinobacter spp. (Table 1 and Figure 6). Such combined nitrificationdenitrification metabolism has been reported for many groups of heterotrophic AOB (Guo et al., 2013; Stein, 2016 and references therein). The genome insights on BML MBAE14 revealed here suggest this organism is a heterotrophic ammonia-oxidizer which conducts a combined nitrification and denitrification process, while relying on organic carbon for growth.

The putative heterotrophic AOB, BML MBAE14 group, and the autotrophic AOB Nitrosomonadaceae (Betaproteobacteriales) appear to be the key ammonia-oxidizers in Base Mine Lake, although the activities of eukaryotes in this system were not evaluated in our metagenomics analyses. Interestingly, these nitrifiers co-occur in time, but their abundances are spatially (depth) separated, presumably driven by the available dissolved oxygen, i.e., while the autotrophic nitrifiers (Nitrosomonadaceae and putative nitrite-oxidizing Chloroflexi) were more abundant within the shallower, more oxygenated epilimnetic and metalimnetic zones, MBAE14 dominated the community in the hypolimnetic region (2-2.5 meters above the FFT-water interface), where oxygen concentrations were lower $(<16 \mu \mathrm{M}=\sim 0.5 \mathrm{mg} / \mathrm{L}$; Figure 3). Our results are consistent with the dominance of heterotrophic AOB over autotrophic AOB under oxygen limiting concentrations ( $<1 \mathrm{mg} / \mathrm{L}$ ) (van Niel et al., 1993; Kampschreur et al., 2009). Heterotrophic ammonia oxidation exhibits 100-1000 times slower rates compared to autotrophic ammonia oxidation (Kampschreur et al., 2009), and the spatial separation of these organisms observed here suggests geochemical conditions segregate autotrophic and heterotrophic ammonia oxidation pathways within the water cap. Although MBAE14 seems adapted to the hypolimnetic hypoxic zones, its growth (iRep inferred) activity was higher within the more oxygenated metalimnetic region than in the hypolimnion (Figure 3). The geochemical results indicate that the Base Mine Lake water cap metalimnetic region comprises opposing concentration gradients of ammonia and oxygen (Figures 1C, 3), suggesting a hotspot for microbial ammonia oxidation (Figure 7). In contrast, concentrations of the three $\mathrm{N}$ redox species barely changed above the metalimnion, suggesting microbial nitrification was less active in the upper water zone compared to the deeper zone, although ammonia was available $(\sim 35 \mu \mathrm{M})$ even at the water surface (Figure 1C and Supplementary Table S1). Methanotrophy, on the other hand, mostly occurred within the lower hypolimnion, which is consistent with the abundance and activity of the methanotrophic Methylococcales (Figures 2, 3, 7) and the occurrence of dissolved aqueous methane above trace concentrations (i.e., $>1 \mu \mathrm{M}$ ) only within the lower hypolimnetic waters (Figure 1C).

Oxygen appeared as a key factor for the distribution of MBAE14 as well as other nitrifiers. Indeed, the absence of 


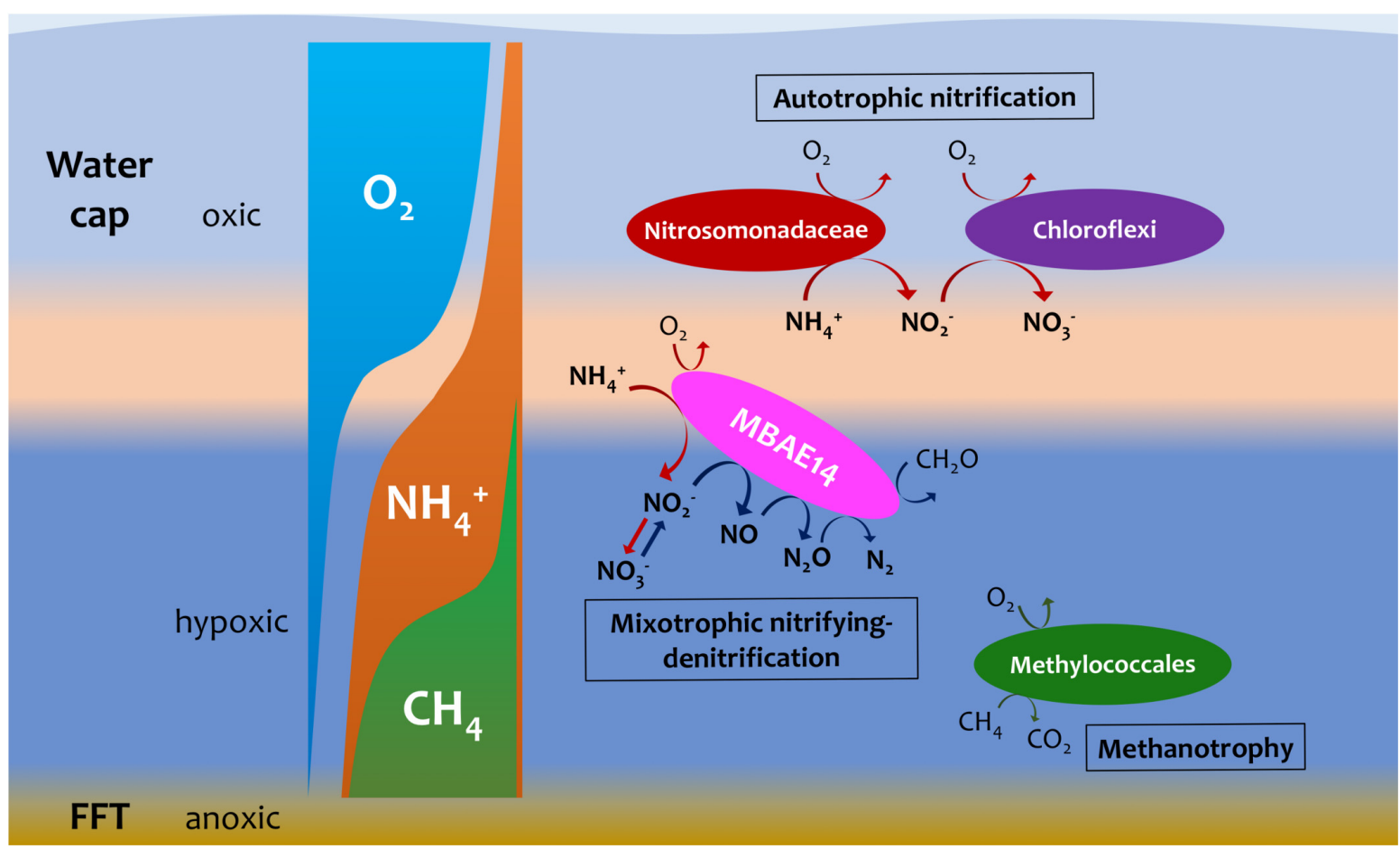

FIGURE 7 | Hypothetic, schematic model summarizing nitrogen and methane biogeochemistry in the summer stratified Base Mine Lake water column (August 2015 and 2016 respectively). A novel gammaproteobacterial group MBAE14 (proposed mixotrophic nitrifying-denitrifier), thrives at the oxic/hypoxic zones of Base Mine Lake water cap separated from autotrophic aerobic nitrifiers (Nitrosomonadaceae and nitrite-oxidizing Chloroflexi). The metalimnetic oxygen-ammonia transition zone (light orange) is suggested as the hotspot for aerobic nitrification by different nitrifiers, while methanotrophy (conducted by Methylococcales) primarily occurs in the hypoxic lower hypolimnetic zones where elevated concentrations of dissolved methane were observed.

any of these nitrifiers in the underlying anoxic FFT suggests these groups are not able to survive without the capability to carry out aerobic nitrification and were thus outcompeted by anaerobes. Expected anaerobic AOB (anammox) groups (i.e., Planctomycetes), as well as the functional genes for anaerobic ammonia oxidation ( $h z s$ and $h d h$ ) were not detected in samples from the Base Mine Lake water column. This result suggests their exclusion is potentially due to the limited nitrite supply, and/or the high bulk organic carbon content of Base Mine Lake water, as anammox pathways are preferentially observed in organic matter-limited environments (Kumar et al., 2017). These results reveal that the ammonia-rich oxic/hypoxic transition zone occurring within the Base Mine Lake hypolimnetic region of the water cap provides a unique nitrogen cycling niche required by this novel, putative heterotrophic nitrifier MBAE14.

\section{The Nitrogen/Carbon Utilization Potential of the MBAE14 Group}

The well-studied aerobic nitrifiers which oxidize: (1) ammonia to nitrite belong to Gammaproteobacteria (Nitrosomonas and Nitrosospira in the order Betaproteobacteriales, and Nitrosococcus) and Thaumarchaeota (Nitrosopumilus); (2) nitrite to nitrate belong to Alphaproteobacteria (Nitrobacter), Gammaproteobacteria (Nitrococcus) and Deltaproteobacteria (Nitrospina); and (3) Nitrospira which are capable of completely oxidizing ammonia to nitrate (comammox). Heterotrophic ammonia oxidation has been reported in various prokaryotes and also eukaryotes (fungi and algae; Schmidt et al., 2003). Indeed, many heterotrophic AOB such as Pseudomonas spp., Alcaligenes spp., Bacillus spp., and Paracoccus spp., are known to conduct combined nitrification and aerobic denitrification (supposedly do not gain energy for growth through nitrification) in soils, sewage sludges, bioreactors and wastewater (Stein, 2016 and references therein). This process has been attracting interest due to its potentially important contribution to the nitrogen cycle in natural environments such as soils (Banerjee and Siciliano, 2012), as well as for its efficiency for removal of nitrogen species which can be applied to wastewater treatments (Joo et al., 2005; Duan et al., 2015). Importantly, homologous genes of amo and hao were not found in genomes of these known heterotrophic AOB (such as Pseudomonas stutzeri, Alcaligenes faecalis, and Paracoccus pantotrophus, Table 1), suggesting these marker genes are conserved only among the autotrophic nitrifiers. The potential $\mathrm{AOB}$ and $\mathrm{HAO}$ enzymes detected from heterotrophic $\mathrm{AOB}$ are sequentially and structurally different from those of autotrophic $\mathrm{AOB}$, suggesting heterotrophic $\mathrm{AOB}$ are incapable of energy-generating nitrification (Bothe et al., 2000). The presence of amo and hao homologous genes in the genome of BML MBAE14 (Figures 5B,C and Table 1) infers that BML MBAE14 possibly utilizes ammonia as an additional or sole energy source, conducting mixotrophic (i.e., chemolitho-heterotrophic) growth 
in addition to denitrification. However, we could not detect the haoB gene in the MBAE14 genome, which is well conserved in genomes of autotrophic AOB (IMG database), implying a different gene/enzyme might be involved. Many autotrophic AOB are also capable of denitrification in addition to energygenerating nitrification, known as the nitrifier denitrification pathway; this metabolism usually happens under severe hypoxic conditions (Poth and Focht, 1985; Shaw et al., 2006) similar to the conditions of the Base Mine Lake hypolimnion where BML MBAE14 was detected. Further, other well-known AOB such as Nitrosomonas have been reported to grow mixotrophically, indicating high functional flexibility of AOB (Hommes et al., 2003). Indeed, the nitrifier denitrification process is thermodynamically favorable $\left(\Delta \mathrm{G}^{0}=-360 \mathrm{~kJ}\right)$ (Broda, 1977) and eventually generates comparable energy to organotrophic denitrification on acetate in oxygen-limited environments $\left(\Delta \mathrm{G}^{0}=-398 \mathrm{~kJ}\right)$, indicating the ecological likelihood and relevance of this pathway (Lam and Kuypers, 2011).

To the best of our knowledge, no cultivation or genomic characterization for the other members belonging to MBAE14 group have been conducted prior to this study. Indeed, the ecology of this group is poorly understood and few studies/environments report their presence; previous occurrences are limited to Arctic deep sea sediments (Li et al., 2015), coastal subsurface sediments (Gupta et al., 2009), and surface seawater where strains were recovered by highthroughput cultivation (Yang et al., 2016). Interestingly, none of these environments are characterized by high ammonia concentrations, however, Li et al. (2015) found the Arctic deep sea sediment enriched with ammonia-oxidizing Thaumarchaeota known to play a major role in ammonia oxidation in oxygenlimited environments (Yan et al., 2012). Although this finding may suggest that marine and freshwater/brackish members of the MBAE14 group present a different affinity for ammonia, it is clear that further research is needed to characterize the diversity and environmental distribution of this MBAE14 group which appears to expand possible nitrogen cycling pathways. Our integrated geochemical-metagenomic approach presents the first insights into the metabolic potential of the MBAE14 group, and further cultivation-based characterization followed by stable isotope analyses and/or transcriptomics approach are expected to fully constrain the nitrogen/carbon utilization capabilities of this group.

\section{CONCLUSION}

Engineered systems provide opportunities to discover novel microorganisms driving putative and yet to be identified metabolic processes harbored in their unusual physicochemical and geochemical contexts. Here, we report on a currently unclassified gammaproteobacterial group MBAE14 from Base Mine Lake, the first full-scale demonstration pit lake in the Athabasca oil sands region, that appears capable of both nitrification and denitrification, adding to our understanding of the nitrogen cycle. Our combined metagenome and geochemical results point to spatial segregation of nitrogen cycling by
MBAE14 within the water cap, dependent on geochemical conditions. Water cap depth dependent opposing gradients of ammonia and oxygen create specialized conditions enabling MBAE14 to carry out aerobic, chemolithotrophic ammonia oxidation at the metalimnetic oxycline where oxygen concentrations are higher, whilst dominating the hypolimnetic hypoxic zones ( $<0.5 \mathrm{mg} / \mathrm{L}$ dissolved oxygen), where it conducts denitrification converting nitrate/nitrite to dinitrogen associated with the mixotrophic nitrifier denitrification pathway. The limitation of labile organic carbon, occurrence of depth dependent geochemical niches and flexibility of MBAE14 nitrogen metabolic pathways, collectively enable this organism to thrive in co-occurrence with other aerobic heterotrophs under higher oxygen concentrations in the metalimnion, as well as with methanotrophs under low oxygen conditions in the hypolimnion. Our results highlight the need for more metagenomics microbial functional gene surveys in these ecologically dynamic systems to better inform our understanding of important biogeochemical cycles.

\section{DATA AVAILABILITY STATEMENT}

The datasets generated for this study can be found in the PRJNA552483 and PRJEB32633.

\section{AUTHOR CONTRIBUTIONS}

JM and LW designed the experiments and prepared the manuscript and figures, incorporating input from all authors. JM, GJ, SR, JM, and ML were responsible for field sampling, geochemical analysis, microbial DNA extraction, and 16S rRNA sequence analysis and interpretation (JM and GJ for the water cap; SR, JM, and ML for the underlying FFT layers). GS provided input on field sampling methods and geochemical analysis. L-XC and JB contributed to the metagenomic analysis and interpretation (de novo assembly, genome binning, and iRep analysis).

\section{FUNDING}

This work was funded by NSERC (CRDPJ 488301-15) and COSIA.

\section{ACKNOWLEDGMENTS}

The authors thank the Syncrude Canada Limited, Reclamation and Closure Research Group, and Tara Colenbrander Nelson for field sampling support.

\section{SUPPLEMENTARY MATERIAL}

The Supplementary Material for this article can be found online at: https://www.frontiersin.org/articles/10.3389/fmicb.2019. 02435/full\#supplementary-material 


\section{REFERENCES}

Banerjee, S., and Siciliano, S. D. (2012). Factors driving potential ammonia oxidation in Canadian arctic ecosystems: does spatial scale matter? Appl. Environ. Microbiol. 78, 346-353. doi: 10.1128/AEM.06132-11

Bartram, A. K., Lynch, M. D. J., Stearns, J. C., Moreno-Hagelsieb, G., and Neufeld, J. D. (2011). Generation of multimillion-sequence 16S rRNA gene libraries from complex microbial communities by assembling paired-end Illumina reads. Appl. Environ. Microbiol. 77, 3846-3852. doi: 10.1128/AEM.02772-10

Bates, S. T., Berg-Lyons, D., Caporaso, J. G., Walters, W. A., Knight, R., and Fierer, N. (2010). Examining the global distribution of dominant archaeal populations in soil. ISME J. 5, 908-917. doi: 10.1038/ismej.2010.171

Bothe, H., Jost, G., Schloter, M., Ward, B. B., and Witzel, K.-P. (2000). Molecular analysis of ammonia oxidation and denitrification in natural environments. FEMS Microbiol. Rev. 24, 673-690. doi: 10.1111/j.1574-6976.2000.tb00566.x

Broda, E. (1977). Two kinds of lithotrophs missing in nature. Z. Allg. Mikrobiol. 17, 491-493. doi: 10.1002/jobm.19770170611

Brown, C. T., Hug, L. A., Thomas, B. C., Sharon, I., Castelle, C. J., Singh, A., et al. (2015). Unusual biology across a group comprising more than $15 \%$ of domain Bacteria. Nature 523, 208-211. doi: 10.1038/nature14486

Brown, C. T., Olm, M. R., Thomas, B. C., and Banfield, J. F. (2016). Measurement of bacterial replication rates in microbial communities. Nat. Biotechnol. 34, 1256-1263. doi: 10.1038/nbt.3704

Brune, A., Frenzel, P., and Cypionka, H. (2000). Life at the oxic-anoxic interface: microbial activities and adaptations. FEMS Microbiol. Rev. 24, 691-710. doi: 10.1016/s0168-6445(00)00054-1

Callahan, B. J., McMurdie, P. J., Rosen, M. J., Han, A. W., Johnson, A. J. A., and Holmes, S. P. (2016). DADA2: high-resolution sample inference from Illumina amplicon data. Nat. Methods 13, 581-583. doi: 10.1038/nmeth.3869

Caporaso, J. G., Lauber, C. L., Walters, W. A., Berg-Lyons, D., Huntley, J., Fierer, N., et al. (2012). Ultra-high-throughput microbial community analysis on the Illumina HiSeq and MiSeq platforms. ISME J. 6, 1621-1624. doi: 10.1038/ismej. 2012.8

Caporaso, J. G., Lauber, C. L., Walters, W. A., Berg-Lyons, D., Lozupone, C. A., Turnbaugh, P. J., et al. (2011). Global patterns of $16 \mathrm{~S}$ rRNA diversity at a depth of millions of sequences per sample. Proc. Natl. Acad. Sci. U.S.A. 108, 4516-4522. doi: 10.1073/pnas.1000080107

Cappello, S., and Yakimov, M. M. (2010). "Oleiophilus," in Handbook of Hydrocarbon and Lipid Microbiology, ed. K. N. Timmis, (Berlin: Springer), 1749-1754. doi: 10.1007/978-3-540-77587-4_124

Chalaturnyk, R. J., Don Scott, J., and Özüm, B. (2002). Management of oil sands tailings. Pet. Sci. Technol. 20, 1025-1046. doi: 10.1081/LFT- 120003695

Daims, H., Lebedeva, E. V., Pjevac, P., Han, P., Herbold, C., Albertsen, M., et al. (2015). Complete nitrification by Nitrospira bacteria. Nature 528, 504-509. doi: 10.1038/nature16461

Dionisi, H. M., Layton, A. C., Harms, G., Gregory, I. R., Robinson, K. G., and Sayler, G. S. (2002). Quantification of Nitrosomonas oligotropha-like ammoniaoxidizing bacteria and Nitrospira spp. from full-scale wastewater treatment plants by competitive PCR. Appl. Environ. Microbiol. 68, 245-253. doi: 10.1128/ AEM.68.1.245-253.2002

Dompierre, K. A., Barbour, S. L., North, R. L., Carey, S. K., and Lindsay, M. B. J. (2017). Chemical mass transport between fluid fine tailings and the overlying water cover of an oil sands end pit lake. Water Resour. Res. 53, 4725-4740. doi: 10.1002/2016WR020112

Dompierre, K. A., Lindsay, M. B. J., Cruz-Hernández, P., and Halferdahl, G. M. (2016). Initial geochemical characteristics of fluid fine tailings in an oil sands end pit lake. Sci. Total Environ. 556, 196-206. doi: 10.1016/j.scitotenv.2016. 03.002

Duan, J., Fang, H., Su, B., Chen, J., and Lin, J. (2015). Characterization of a halophilic heterotrophic nitrification-aerobic denitrification bacterium and its application on treatment of saline wastewater. Bioresour. Technol. 179, 421-428. doi: 10.1016/j.biortech.2014.12.057

Edgar, R. C. (2010). Search and clustering orders of magnitude faster than BLAST. Bioinformatics 26, 2460-2461. doi: 10.1093/bioinformatics/btq461

Foght, J. M., Gieg, L. M., and Siddique, T. (2017). The microbiology of oil sands tailings: past, present, future. FEMS Microbiol. Ecol. 93, 1-22. doi: 10.1093/ femsec/fix034
Gauthier, M. J., Lafay, B., Christen, R., Fernandez, L., Acquaviva, M., Bonin, P., et al. (1992). Marinobacter hydrocarbonoclasticus gen. nov., sp. nov., a new, extremely halotolerant, hydrocarbon-degrading marine bacterium. Int. J. Syst. Evol. Microbiol. 42, 568-576. doi: 10.1099/00207713-42-4-568

Geets, J., Boon, N., and Verstraete, W. (2006). Strategies of aerobic ammoniaoxidizing bacteria for coping with nutrient and oxygen fluctuations. FEMS Microbiol. Ecol. 58, 1-13. doi: 10.1111/j.1574-6941.2006.00170.x

Giblin, A. E., Tobias, C. R., Song, B., Weston, N., Banta, G. T., and Rivera-Monroy, V. H. (2013). The importance of dissimilatory nitrate reduction to ammonium (DNRA) in the nitrogen cycle of coastal ecosystems. Oceanography 26, 124-131. doi: 10.5670/oceanog.2013.54

Guo, J., Peng, Y., Wang, S., Ma, B., Ge, S., Wang, Z., et al. (2013). Pathways and organisms involved in ammonia oxidation and nitrous oxide emission. Crit. Rev. Environ. Sci. Technol. 43, 2213-2296. doi: 10.1080/10643389.2012.672072

Gupta, A. K., Rangrez, A. Y., Verma, P., Chatterji, A., and Shouche, Y. S. (2009). Phylogenetic profiling of bacterial community from two intimately located sites in Balramgari, North-East coast of India. Indian J. Microbiol. 49, 169-187. doi: 10.1007/s12088-009-0034-9

Hommes, N. G., Sayavedra-Soto, L. A., and Arp, D. J. (2003). Chemolithoorganotrophic growth of Nitrosomonas europaea on fructose. J. Bacteriol. 185, 6809-6814. doi: 10.1128/JB.185.23.6809-6814.2003

Hyatt, D., Chen, G.-L., LoCascio, P. F., Land, M. L., Larimer, F. W., and Hauser, L. J. (2010). Prodigal: prokaryotic gene recognition and translation initiation site identification. BMC Bioinformatics 11:119. doi: 10.1186/1471-2105-11-119

Jetten, M. S. M., Strous, M., van de Pas-Schoonen, K. T., Schalk, J., van Dongen, U. G. J. M., Logemann, S., et al. (1998). The anaerobic oxidation of ammonium. FEMS Microbiol. Rev. 22, 421-437. doi: 10.1111/j.1574-6976.1998.tb00379.x

Joo, H.-S., Hirai, M., and Shoda, M. (2005). Characteristics of ammonium removal by heterotrophic nitrification-aerobic denitrification by Alcaligenes faecalis No. 4. J. Biosci. Bioeng. 100, 184-191. doi: 10.1263/jbb.100.184

Joshi, N. A., and Fass, J. N. (2011). Sickle: A sliding-window, adaptive, quality-based trimming tool for FastQ files version 1.33.

Kampschreur, M. J., Temmink, H., Kleerebezem, R., Jetten, M. S. M., and van Loosdrecht, M. C. M. (2009). Nitrous oxide emission during wastewater treatment. Water Res. 43, 4093-4103. doi: 10.1016/j.watres.2009.03.001

Kang, D. D., Froula, J., Egan, R., and Wang, Z. (2015). MetaBAT, an efficient tool for accurately reconstructing single genomes from complex microbial communities. PeerJ 3:e1165. doi: 10.7717/peerj.1165

Könneke, M., Bernhard, A. E., de la Torre, J. R., Walker, C. B., Waterbury, J. B., and Stahl, D. A. (2005). Isolation of an autotrophic ammonia-oxidizing marine archaeon. Nature 437, 543-546. doi: 10.1038/nature03911

Kozich, J. J., Westcott, S. L., Baxter, N. T., Highlander, S. K., and Schloss, P. D. (2013). Development of a dual-index sequencing strategy and curation pipeline for analyzing amplicon sequence data on the MiSeq Illumina sequencing platform. Appl. Environ. Microbiol. 79, 5112-5120. doi: 10.1128/AEM.01043-13

Kumar, S., Herrmann, M., Thamdrup, B., Schwab, V. F., Geesink, P., Trumbore, S. E., et al. (2017). Nitrogen loss from pristine carbonate-rock aquifers of the Hainich Critical Zone Exploratory (Germany) is primarily driven by chemolithoautotrophic anammox processes. Front. Microbiol. 8:1951. doi: 10. 3389/fmicb.2017.01951

Kumar, S., Stecher, G., and Tamura, K. (2016). MEGA7: molecular evolutionary genetics analysis version 7.0 for bigger datasets. Mol. Biol. Evol. 33, 1870-1874. doi: $10.1093 / \mathrm{molbev} / \mathrm{msw} 054$

Kuypers, M. M. M., Marchant, H. K., and Kartal, B. (2018). The microbial nitrogencycling network. Nat. Rev. Microbiol. 16, 263-276. doi: 10.1038/nrmicro. 2018.9

Lam, P., and Kuypers, M. M. M. (2011). Microbial nitrogen cycling processes in oxygen minimum zones. Ann. Rev. Mar. Sci. 3, 317-345. doi: 10.1146/annurevmarine-120709-142814

Langmead, B., and Salzberg, S. L. (2012). Fast gapped-read alignment with Bowtie 2. Nat. Methods 9, 357-359. doi: 10.1038/nmeth.1923

Li, Y., Liu, Q., Li, C., Dong, Y., Zhang, W., Zhang, W., et al. (2015). Bacterial and archaeal community structures in the Arctic deep-sea sediment. Acta Oceanol. Sin. 34, 93-113. doi: 10.1007/s13131-015-0624-9

Lowe, T. M., and Eddy, S. R. (1997). tRNAscan-SE: a program for improved detection of transfer RNA genes in genomic sequence. Nucleic Acids Res. 25, 955-964. doi: 10.1093/nar/25.5.955 
Martin, M. (2011). Cutadapt removes adapter sequences from high-throughput sequencing reads. EMBnet. J. 17, 10-12.

Olm, M. R., Brown, C. T., Brooks, B., and Banfield, J. F. (2017). dRep: a tool for fast and accurate genomic comparisons that enables improved genome recovery from metagenomes through de-replication. ISME J. 11, 2864-2868. doi: 10.1038/ismej.2017.126

Paerl, H. W., and Pinckney, J. L. (1996). A mini-review of microbial consortia: their roles in aquatic production and biogeochemical cycling. Microb. Ecol. 31, 225-247. doi: 10.1007/BF00171569

Parks, D. H., Chuvochina, M., Waite, D. W., Rinke, C., Skarshewski, A., Chaumeil, P.-A., et al. (2018). A standardized bacterial taxonomy based on genome phylogeny substantially revises the tree of life. Nat. Biotechnol. 36, 996-1004. doi: $10.1038 /$ nbt. 4229

Parks, D. H., Imelfort, M., Skennerton, C. T., Hugenholtz, P., and Tyson, G. W. (2015). CheckM: assessing the quality of microbial genomes recovered from isolates, single cells, and metagenomes. Genome Res. 25, 1043-1055. doi: 10. 1101/gr.186072.114

Peng, Y., Leung, H. C. M., Yiu, S. M., and Chin, F. Y. L. (2012). IDBA-UD: a de novo assembler for single-cell and metagenomic sequencing data with highly uneven depth. Bioinformatics 28, 1420-1428. doi: 10.1093/bioinformatics/bts174

Poth, M., and Focht, D. D. (1985). ${ }^{15} \mathrm{~N}$ kinetic analysis of $\mathrm{N}_{2} \mathrm{O}$ production by Nitrosomonas europaea: an examination of nitrifier denitrification. Appl. Environ. Microbiol. 49, 1134-1141.

Risacher, F. F., Morris, P. K., Arriaga, D., Goad, C., Nelson, T. C., Slater, G. F., et al. (2018). The interplay of methane and ammonia as key oxygen consuming constituents in early stage development of Base Mine Lake, the first demonstration oil sands pit lake. Appl. Geochem. 93, 49-59. doi: 10.1016/j. apgeochem.2018.03.013

Rognes, T., Flouri, T., Nichols, B., Quince, C., and Mahé, F. (2016). VSEARCH: a versatile open source tool for metagenomics. PeerJ 4:e2584. doi: 10.7717/peerj. 2584

Satomi, M., and Fujii, T. (2014). "The Family Oceanospirillaceae," in The Prokaryotes: Gammaproteobacteria, eds E. Rosenberg, E. F. DeLong, S. Lory, E. Stackebrandt, and F. Thompson, (Berlin: Springer), 491-527. doi: 10.1007/ 978-3-642-38922-1_286

Schloss, P. D., Westcott, S. L., Ryabin, T., Hall, J. R., Hartmann, M., Hollister, E. B., et al. (2009). Introducing mothur: open-source, platform-independent, community-supported software for describing and comparing microbial communities. Appl. Environ. Microbiol. 75, 7537-7541. doi: 10.1128/AEM. 01541-09

Schmidt, I., Sliekers, O., Schmid, M., Bock, E., Fuerst, J., Kuenen, J. G., et al. (2003). New concepts of microbial treatment processes for the nitrogen removal in wastewater. FEMS Microbiol. Rev. 27, 481-492. doi: 10.1016/S0168-6445(03) 00039-1
Shaw, L. J., Nicol, G. W., Smith, Z., Fear, J., Prosser, J. I., and Baggs, E. M. (2006). Nitrosospira spp. can produce nitrous oxide via a nitrifier denitrification pathway. Environ. Microbiol. 8, 214-222. doi: 10.1111/j.1462-2920.2005.00 882.x

Stein, L. Y. (2016). "Heterotrophic nitrification and nitrifier denitrification," in Nitrification, eds B. Ward, D. Arp, and M. Klotz, (Washington, DC: ASM Press), 95-114. doi: 10.1128/9781555817145.ch5

Syncrude Canada Ltd. (2017). 2016 Summary Report: Base Mine Lake Monitoring and Research Program. Canada: Syncrude Canada Limited.

Thavamani, P., Samkumar, R. A., Satheesh, V., Subashchandrabose, S. R., Ramadass, K., Naidu, R., et al. (2017). Microbes from mined sites: harnessing their potential for reclamation of derelict mine sites. Environ. Pollut. 230, 495-505. doi: 10.1016/j.envpol.2017.06.056

van Kessel, M. A. H. J., Speth, D. R., Albertsen, M., Nielsen, P. H., Op den Camp, H. J. M., Kartal, B., et al. (2015). Complete nitrification by a single microorganism. Nature 528, 555-559. doi: 10.1038/nature16459

van Niel, E. W. J., Arts, P. A. M., Wesselink, B. J., Robertson, L. A., and Kuenen, J. G. (1993). Competition between heterotrophic and autotrophic nitrifiers for ammonia in chemostat cultures. FEMS Microbiol. Lett. 102, 109-118. doi: 10.1016/0378-1097(93)90006-N

White, K. B., and Liber, K. (2018). Early chemical and toxicological risk characterization of inorganic constituents in surface water from the Canadian oil sands first large-scale end pit lake. Chemosphere 211, 745-757. doi: 10.1016/ j.chemosphere.2018.07.059

Yan, J., Haaijer, S. C. M., Op den Camp, H. J. M., Niftrik, L., Stahl, D. A., Könneke, M., et al. (2012). Mimicking the oxygen minimum zones: stimulating interaction of aerobic archaeal and anaerobic bacterial ammonia oxidizers in a laboratory-scale model system. Environ. Microbiol. 14, 3146-3158. doi: 10.1111/ j.1462-2920.2012.02894.x

Yang, S.-J., Kang, I., and Cho, J.-C. (2016). Expansion of cultured bacterial diversity by large-scale dilution-to-extinction culturing from a single seawater sample. Microb. Ecol. 71, 29-43. doi: 10.1007/s00248-015-0695-3

Conflict of Interest: The authors declare that the research was conducted in the absence of any commercial or financial relationships that could be construed as a potential conflict of interest.

Copyright $\odot 2019$ Mori, Chen, Jessen, Rudderham, McBeth, Lindsay, Slater, Banfield and Warren. This is an open-access article distributed under the terms of the Creative Commons Attribution License (CC BY). The use, distribution or reproduction in other forums is permitted, provided the original author(s) and the copyright owner $(s)$ are credited and that the original publication in this journal is cited, in accordance with accepted academic practice. No use, distribution or reproduction is permitted which does not comply with these terms. 